WellBeing International

WBI Studies Repository

1985

\title{
Cardiac Arrest Stunning of Livestock and Poultry
}

Temple Grandin

University of Illinois at Urbana-Champaign

Follow this and additional works at: https://www.wellbeingintlstudiesrepository.org/acwp_faafp

Part of the Agribusiness Commons, Animal Studies Commons, and the Operations and Supply Chain Management Commons

\section{Recommended Citation}

Grandin, T. (1985). Cardiac arrest stunning of livestock and poultry. In M.W. Fox \& L.D. Mickley (Eds.), Advances in animal welfare science 1985/86 (pp. 1-30). Washington, DC: The Humane Society of the United States.

This material is brought to you for free and open access by WellBeing International. It has been accepted for inclusion by an authorized administrator of the WBI Studies Repository. For more information, please contact wbisr-info@wellbeingintl.org.

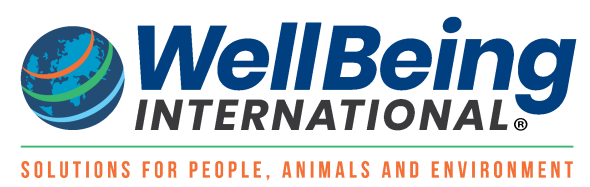




\section{CARDIAC ARREST STUNNING OF LIVESTOCK AND POULTRY}

\section{Temple Grandin}

University of Illinois

Department of Animal Science

1207 West Gregory Drive

Urbana, Illinois 61201

\section{Introduction}

A stunning method that will reliably render an animal insensible to pain and sensation prior to hoisting and bleeding is essential to prevent suffering. Cardiac arrest stunning is more effective than conventional electric stunning. In cardiac arrest stunning, an electric current is passed through both the brain and the heart to produce permanent insensibility. Since the animal is killed by the electricity it cannot revive during hoisting, bleeding, or slaughtering procedures. In contrast, conventional electrical stunning induces reversible insensibility for a short period of time (Hoenderken 1978a; Grandin 1980a; Warrington 1974; Lambooy and Spanjaard 1982; Blackmore and Newhook 1981).

The advantages of cardiac arrest stunning are outlined below. If the interval between removal of the electric stunner and bleeding (throat cutting) is too long or if the throat is cut incorrectly, an animal may enter the scalding tank or have a limb or skin removed while still conscious. Cardiac arrest stunning practically eliminates this possibility compared to conventional electric stunning. Another advantage of cardiac arrest stunning is if the animal accidentally misses the bleeding station, stopping the heart will probably induce unconsciousness prior to the animal's being transported to the scalding tank or the first leg removal or skinning station. It has been shown that sheep become insensible 28 seconds after the heart stops without bleeding (Gregory and Wotton 1984a) Cardiac arrest stunning is recommended for sheep, pigs, calves, and poultry by many researchers in this area, including Blackmore, and Newhook (1981), Gregory and Wotton (1984d), Lambooy and Spanjaard (1982), Heath (1984a), and the Agricultural and Food Council (1984). A third advantage of cardiac arrest is that its use will help reduce injuries to slaughter plant employees from the animals' kicking during bleeding as the spasms associated with conventional 
electric stunning are greatly reduced or eliminated (Gilbert 1980; Gilbert et al. 1984.).

\section{Insensibility Times}

Table 1 shows the period of insensibility which is induced by conventional electric stunning. It also shows the time required for insensibility to occur due to oxygen deprivation from loss of blood, after both correct and incorrect bleeding methods. For futher information on the assessment of insensibility refer to Lopes da Silva (1983) and Blackmore and Newhook (1983). If the time required to induce unconsciousness from bleeding exceeds the length of the insensibility period induced by the stunner, the animal may feel pain and suffer.

Incorrect bleeding methods may greatly extend the time required for unconsciousness to occur from loss of blood. For example, loss of sensibility may be delayed by cutting the blood vessels on only one side of the neck. Blackmore and Petersen (1981) reported that failure to cut the blood vessels on both sides of the neck of sheep occurred 4 to 47 percent of the time, depending on the skills of the individual slaughter worker. Bleeding by an unskilled person may delay the onset of insensibility in pigs to over 60 seconds (Hoenderken 1978b). In poultry, failure to sever the carotids with an automatic neck cutter lengthened the time required for the bird to die (Agricultural and Food Research Council 1984).

Pigs and sheep lose consiousness relatively quickly after bleeding compared to calves (table 1). Studies by different researchers on pigs and sheep have similar results. Sheep lose consciousness quickly after bleeding because the entire brain is supplied by blood from the carotid arteries (Baldwin 1971; Blackmore 1985, personal communication). In calves, however, the brain is supplied by both the carotid and the vertebral arteries (Baldwin 1971). While the carotids are severed during bleeding, the vertebral arteries are not. After the throat is cut, calves may still receive blood to the brain via the vertebral arteries (Newhook and Blackmore 1982; Blackmore 1985, personal communication). Newhook and Blackmore (1982) report that young calves remain sensible for 65 to 85 seconds after the throat is cut with a possible resurgence of sensibility up to 123 to 323 seconds later. In older calves, 31 to 42 days of age, the onset of unconsciousness was 28 to 168 seconds after bleeding (Blackmore et al. 1983). The results of these two studies are in conflict with the findings of Nangeroni and Kennett (1963), Schultze et al. (1978), and Gregory and Wotton (1984b) (table 1). Blackmore et al. (1983) is unable to explain why their results differed from those of Schultze et al. (1978) and Nangeroni and Kennett (1963).

Gregory and Wotton (1984a) state that calves became insensible within 17 seconds. After the throat cut, responsiveness of the brain was 
measured utilizing electrocortigrams while a light was flashed in the calf's eyes.

The retina of the eye fails very quickly when it is deprived of oxygen or blood (U.S. Navy 1968; Fraser 1973). Vision is lost almost instantly when acceleration in a centrifuge forces blood out of the retinal blood vessels (Duane 1954; Newsom et al. 1968). Severance of the carotid arteries during slaughter would cut off the major blood supply to the eye in both calves and sheep thereby causing loss of vision (Blackmore 1985, personal communication).

Vision will fail prior to the onset of unconsciousness (Fraser 1973; U.S. Navy 1968; Vecchio 1977; Chambers 1963), but the auditory system is much more resistant to lack of oxygen (Heath and Williams 1977). There is some evidence that hearing may still be functional during the early stages of unconsciousness (Chambers 1963). New research indicates that visually evoked responses and somatosensory evoked responses disappear at approximately the same time after the throat is cut (N.G. Gregory, 1985, personal communication). After bleeding, visually evoked responses persist in poultry for at least one minute after spontaneous cortical activity has stopped (Daly 1985). At the present time, there is no good explanation for the apparent conflict between Gregory and Wotton (1984a), and Blackmore et al. (1983), and Newhook and Blackmore (1982).

Further studies by Blackmore (1984) indicate a large difference in the reactions of sheep and calves after the carotid arteries and jugular veins were cut. Sheep and lambs ceased coordinated attempts to rise after 8 to 11 seconds, and 1 to 7 day old calves stopped attempting to rise at an average of 39 seconds. If one carotid becomes occluded, the time was extended to 385 seconds. The time for an adult bull was 20 seconds.

A stunning method which produces either permanent or prolonged insensibility is essential for humane stunning of calves (Lambooy and Spanjaard 1982; Newhook and Blackmore 1982). I have observed calves reviving during bleeding in slaughter plants when conventional electric stunning was used. Calves may revive even if they are bled immediately after conventional electric stunning. In sheep and pigs, bleeding should take place within 10 to 17 seconds after conventional stunning to insure that the animals do not return to sensibility (Lambooy 1982; Blackmore and Newhook 1981; Leach 1978). In pigs, the absolute maximum allowable interval is 30 seconds (Hoenderken 1978a). Too long an interval between conventional electric stunning and bleeding is, unfortunately, a common occurrence in some slaughter plants (Gregory and Wotton 1984c). 
Table 1. Insensibility times.

\begin{tabular}{|c|c|c|c|}
\hline & Conventional Electric Stunning & Correct Bleeding Method & Incorrect Bleeding Method \\
\hline Species & Insensibility period & $\begin{array}{l}\text { Onset of insensibility due to } \\
\text { hypoxia anoxia from bleeding }\end{array}$ & $\begin{array}{l}\text { Onset of insensibility due to } \\
\text { hypoxia anoxia from bleeding }\end{array}$ \\
\hline \multirow[t]{5}{*}{ Sheep } & $\begin{array}{l}\text { 18-42 sec. (Blackmore \& } \\
\text { Newhook 1982) }\end{array}$ & $\begin{array}{l}2-7 \text { sec. (Newhook \& } \\
\text { Blackmore 1982) }\end{array}$ & 29 sec. (Newhook \& Blackmore 1982) \\
\hline & $\begin{array}{l}22 \text { minumum sec. } X=43 \text { (Lambooy } \\
\text { 1982) }\end{array}$ & $\begin{array}{l}14 \text { sec. Visual evoked potential } \\
\text { (Gregory \& Wotton 1984) }\end{array}$ & $70-298$ sec. (Gregory \& Wotton 1984 ) \\
\hline & & $\begin{array}{l}3.3-6.2 \text { sec. (Nangeroni \& Kennett } \\
1963 \text { ) }\end{array}$ & \\
\hline & & 4-6 sec. (Schulze et al. 1978) & \\
\hline & & $\begin{array}{l}\text { 8-11 sec. Stops attempts to stand } \\
\text { (Blackmore 1984) }\end{array}$ & \\
\hline \multirow[t]{2}{*}{ Pigs } & $\begin{array}{l}32 \text { minimum sec. } X=66 \\
\text { (Hoenderken 1978) }\end{array}$ & 12-20 sec. (Hoenderken 1978b) & $12-62+$ sec. (Hoenderken 1978b) \\
\hline & $\begin{array}{l}34.8 \text { sec. } \pm 12.45 \text { (Swatland et al. } \\
1984 \text { ) }\end{array}$ & $\begin{array}{l}25 \text { sec. (Blackmore \& Newhook } \\
\text { 1981) }\end{array}$ & \\
\hline
\end{tabular}




\begin{tabular}{|c|c|c|c|}
\hline \multicolumn{4}{|l|}{ Calves \& Cattle } \\
\hline \multirow[t]{3}{*}{1 week old } & & $\begin{array}{l}39 \text { sec. Stops attempt to stand } \\
\text { (Blackmore 1984) }\end{array}$ & \multirow{3}{*}{$\begin{array}{l}385 \text { sec. Stops attempts to stand. } \\
\quad \text { (Blackmore 1984) }\end{array}$} \\
\hline & & $\begin{array}{l}65-85 \text { sec. up to } 123-323 \text { onset } \\
\text { Resurgence of possible sensibility } \\
\text { (Blackmore et al. 1983b) }\end{array}$ & \\
\hline & & $\begin{array}{l}17 \text { sec. Visual evoked potential } \\
\text { (Gregory \& Wotton 1984b) }\end{array}$ & \\
\hline \multirow[t]{2}{*}{$4^{1 / 2}$ to 8 weeks old } & $\begin{array}{l}\text { 36-61 sec. (Blackmore \& Newhook } \\
\text { 1982) }\end{array}$ & $\begin{array}{l}4.4-6.9 \text { sec. (Nangeroni \& Kennett } \\
1983 \text { ) }\end{array}$ & \\
\hline & & $28-168$ sec. (Blackmore et al. 1983) & \\
\hline \multirow[t]{2}{*}{$\begin{array}{l}6 \text { months } \\
\text { to adults }\end{array}$} & $\begin{array}{l}21-41 \text { sec. (Lambooy \& Spanjaard } \\
\text { 1982) }\end{array}$ & 10 sec. (Levinger 1979) & $\begin{array}{l}60+\text { sec. Walking around (Grandin } \\
1980\end{array}$ \\
\hline & & $\begin{array}{l}20 \text { sec. Stops attempts to stand } \\
\text { (Blackmore 1984) }\end{array}$ & \\
\hline \multirow[t]{2}{*}{ Chickens } & $30-60$ sec. (Richards \& Sykes 1967) & 60 sec. (Gregory \& Wotton 1985 ) & 122 sec. (Gregory \& Wotton 1985 ) \\
\hline & $\begin{array}{l}60 \text { sec. maximum (Kuenzel \& } \\
\text { Walther } 1978 \text { ) }\end{array}$ & & \\
\hline
\end{tabular}

Note: All studies electroencephalographic or electrocorticograms unless noted. 


\section{Cardiac Arrest Stunning}

To reliably induce instantaneous insensibility, an electric current must pass through the brain (Grandin 1980a; Croft 1952; Hoenderken 1978a; Roberts 1954). Enough voltage must be applied to force a sufficient current (amperage) through the brain. Only a small portion of the total applied current actually goes through the brain (Swatland et al. 1984); the rest of the current remains on the surface.

Cardiac arrest stunning can be done three different ways: head-toback; head-to-leg, -brisket, or -groin; and sequential stun (Gilbert 1980; Lambooy and Spanjaard 1982; Blackmore and Petersen 1981). The electrode which is placed on the head is similar to the electrodes used for conventional electric stunning. The head electrode may be placed on the forehead, on the sides or top of the head, or immediately behind the ears (Grandin 1980a; Hoenderken 1978a; Croft and Hume 1956; Gregory and Wotton 1984d). The head electrode must never be placed on the neck. It is possible to induce cardiac arrest with a head-only stunner, but very high voltages and amperages must be used. A high voltage head-only stunner will not reliably stop the heart in all the animals. When cardiac arrest stunning methods fail to produce cardiac arrest, the animals will be rendered temporarily insensible in the same manner as conventional stunning.

\section{Differences in Sensitivity and Variability}

There are large differences in the sensitivity to electricity of different species, and in animals from different regions as well. A stunner setting which will reliably induce cardiac arrest in pigs in one slaughter plant may not reliably induce it in another. Practical experience and research data indicate that an animal's sensitivity to electricity can be affected by factors such as weight, fat thickness, access to drinking water prior to stunning, wetness of the skin, mineral content or salt content in the water which is on the skin, wool or hair coat length, skin thickness and age (Croft 1952; Hoenderken 1978a). A dry pig has twice as much resistance compared to a wet pig, and pigs with thick backfat had a higher resistance (Solis Cortes 1984, personal communication). Old laying hens with scaly legs have a higher electrical resistance than young broilers (Schutt-Abraham et al. 1983). Pigs which have had continuous access to water are easier to stun (Croft 1952). Calves have a lower resistance than pigs (Lambooy and Spanjaard 1982). Another factor which may influence the amount of voltage to induce cardiac arrest is animal contact with electrical grounds (Grandin 1980a). A portion of the electric current may pass through the restrainer or floor instead of between the electrodes. The restrainer should be insulated to isolate the animal from electrical grounds (Grandin 1980a). This 
is especially important for pigs and calves because they are not covered with insulating wool. The animal should not contact bolts or metal structures which are grounded during stunning. The restrainer should also be examined to make sure that dripping water is not creating electrical grounds. Cardiac arrest stunning can be applied either manually or by an automatic stunner. Three advantages of an automatic system are: safety for employees; consistency because it will not become tired, careless, or sadistic; and labor reduction. Automatic stunners should be rugged, simple, and reliable. Proper maintenance and adjustment is essential to insure that instantaneous unconsciousness is reliably produced.

\section{Electrical Characteristics}

The use of a power supply that maintains a constant current (amperage) is recommended. Constant current power sources are used in New Zealand, which is a leader in cardiac arrest stunning technology (Blackmore and Petersen 1981). A constant current power source maintains the amperage setting, and voltage fluctuates depending on the resistance of the animal. It is the current which induces unconsciousness (Hoenderken 1978a) and stops the heart. The voltage is the pressure which pushes the current through the animal. Less sophisticated stunners have a constant voltage power source and the current level fluctuates with animal resistance. Thus, the use of a constant voltage power supply is likely to produce erratic results.

The frequency and waveform of the stunning current can affect its ability to induce unconsciousness. Most stunners in the United States and Europe operate on 50 to $60 \mathrm{~Hz}$ alternating current (AC). This is the standard frequency supplied by the power company. High frequencies are less likely to induce unconsciousness compared with 50 to 60 $\mathrm{Hz}$. Croft reported that frequencies between 50 to $200 \mathrm{~Hz}$ are suitable for stunning; frequencies under $25 \mathrm{~Hz}$ or over $500 \mathrm{~Hz}$ do not induce unconsciousness (Croft 1952). Hoenderken (1978a) reports that unconsciousness can be more effectively induced at $50 \mathrm{~Hz}$ compared to $1800 \mathrm{~Hz}$. High frequencies, it was noted by Van der Wal (1978), seemed to cause pain but these frequencies provide meat quality advantages (Marple 1977; Warrington 1974). High frequencies are less capable of inducing unconsciousness because they stay on the surface of the animal (Horst 1984, personal communication) and stunners with such frequencies that cause pain or fail to produce instant unconsciousness would not be acceptable from an animal welfare viewpoint. Changing the waveform may produce meat quality improvements without compromising animal welfare. The use of $150 \mathrm{~Hz}$ square waves on humans reliably induced a seizure and unconsciousness with a 50 percent reduction in energy (Weaver et al. 1977). 
T. Grandin

\section{Cardiac Arrest Stunning State of the Art}

\section{Sheep}

Cardiac arrest stunning has been used successfully in New Zealand for many years. For all cardiac arrest stunning methods, the sheep are held in a conveyor restrainer or a restraining chute. As sheep have insulating wool, the electrodes must be designed so as to insure good contact. Manual head-to-back cardiac arrest stunners in New Zealand have a $31 / 8$ in $\times 3 \frac{1}{8}$ in $(8 \mathrm{~cm} \times 8 \mathrm{~cm})$ saddle-shaped electrode which is placed on the back over the heart and two pegs which are placed on the head. Water jets in the pegs and in the saddle electrode provide good electrical contact through the wool (Frazerhurst 1975). This method is superior to sharp pin electrodes. The electrodes are spaced 16 in $(40 \mathrm{~cm}$ ) apart (Gilbert and Devine 1982). Some slaughter plants space electrodes 10 in $(26 \mathrm{~cm})$ to $131 / 2$ in $(34.5 \mathrm{~cm})$. The two pegs on the head are spaced $11 / 4$ in $(3 \mathrm{~cm})$ apart. The electric current passes from the head electrodes to the back electrodes (Gilbert and Devine 1982).

In head-to-leg stunning, the electric current passes from the head electrodes to a leg electrode which is mounted on the bottom of the conveyor restrainer. To make contact through the wool, water jets wet the legs. Best results are obtained when the leg electrode makes good contact with the front feet. Automatic head-to-leg stunners have been developed in New Zealand.

Blackmore and Petersen (1981) report that 3 seconds' stunning at 0.8 amps at 400 volts and $50 \mathrm{~Hz}$ induced cardiac arrest 89.3 percent of the time using head-to-rear legs contacts and 96.8 percent using head-to-forelegs. Due to the wool covering, sheep are the most difficult animal on which to achieve a good electrical contact. Typical New Zealand sheep stunning equipment has a maximum output of 400 volts and is adjustable from 0.5 to 2 amps (Blackmore and Petersen 1981). Settings used to induce cardiac arrest and unconsciousness in sheep varied from 0.7 to 2 amps for 3 to 4 seconds (Gilbert 1980). The voltage varies from 100 to 400 volts depending on the sheep's resistance. Settings of $1 \mathrm{amp}$, at 300 to 400 volts, $50 \mathrm{~Hz}$ for 3 seconds produced unconsciousness and cardiac arrest in 100 percent of adult sheep and lambs (Gregory and Wotton 1984d). A head-to-back stunner with a 15 in $(38 \mathrm{~cm})$ electrode spacing was used. Unconsciousness was determined by an epileptiform response on an EEG.

Another cardiac arrest stunning method is split current or sequential stunning. A high current and voltage is used for the initial head stun to induce insensibility, followed by a lower current used to induce cardiac arrest (Gregory and Wotton 1984d; Gilbert et al. 1984). Gregory et al. (1984) used tongs to head stun sheep for 3 seconds at 300 volts $50 \mathrm{~Hz}, 50$ volts were then applied across the chest. Gilbert et al. (1984) 
applied 0.75 to $1 \mathrm{amp} 50 \mathrm{~Hz}$ to the head for 4 seconds with two electrodes spaced $8 \mathrm{~cm}$ apart. The heart was stopped two seconds later with a second $0.3 \mathrm{amp}$ current which passed from one foreleg to the other for 4 seconds. To prevent kicking, a third $0.9 \mathrm{amp}$ current was passed from the head to the groin after a delay of 1 to 20 seconds. It was found that 100 volts was the minimum to stop the heart after the head stun. During these experiments, the researchers restrained the sheep by placing them astride a $10 \mathrm{~cm}$ (4 in) wide padded bar. This type of restrainer is similar to the one described by Giger et al. (1977).

Gilbert et al. (1984) also experimented with different frequencies to stop the heart. Square waves at 14.3 to $40 \mathrm{~Hz}$ and $1000 \mathrm{~Hz}$ at 400 volts failed to stop the heart, as did square waves (alternating current) at $14.3 \mathrm{~Hz}$ at 400 volts. Alternating current of $50 \mathrm{~Hz}$ was found to be the most effective.

\section{Pigs}

There has been relatively little formal research on cardiac arrest stunning of pigs. Hoenderken (1978a, 1983) found that 1.25 amps 50 $\mathrm{Hz}$ at 300 volts for 1 second was the minimum required for reliable induction of instantaneous unconsciousness in pigs. Practical experience in the United States and Canada indicates that cardiac arrest can be induced with a head-to-back stunner with a wide, blunt, flat electrode or two non-penetrating peg electrodes on the forehead, or immediately behind the ears, and a wide saddle-shaped electrode placed on the back. The wide surface area reduces electrical resistance. The electrodes are spaced $12(30 \mathrm{~cm})$ to 18 in $(36$ to $41 \mathrm{~cm})$ apart. Fourteen to 16 inches $(35.5$ to $46 \mathrm{~cm}$ ) is the most common spacing. Pigs must be wetted before the stunner is applied (Hoenderken 1978a). Water sprays should be located in the chute where the pigs wait in line to enter the stunning restrainer. Care must be taken that the animals are not dripping wet, as excessive water dripping off the pigs may create undesirable electrical grounds.

Preliminary tests with head-to-foreleg stunning indicated that 300 volts, at 1.5 amps for 1 to 2 seconds induced cardiac arrest in pigs (Swilley 1985, personal communication). Some slaughter plants that did not have constant amperage power units had difficulty inducing cardiac arrest with a head-to-back stunner even when the voltage was considerably higher than 300 volts. Due to the insulating layer of backfat on pigs, head-to-leg may be the preferred cardiac arrest method for pigs.

Many small plants stun pigs on the floor without a restrainer. In England, some plants used standard stunning tongs to stop the heart in pigs. The 90 volt, $50 \mathrm{~Hz}$ tongs are first applied to the head in the conventional manner for 15 seconds. After head stunning, the tongs are clamped on the pig's body for 5 seconds (Warriss and Wotton 1981). It is essential that the tongs are placed on the head first. This method 


\section{Effects on Processing}

\section{Stillness}

When conventional head-only stunning is used, the animal will kick violently due to the grand mal seizure which is induced by the stunner. A grand mal seizure must occur to make the animal or bird unconscious (Hoenderken 1978a; Warrington 1974; Croft 1952; Croft and Hume 1956). The spasms and contractions associated with the seizure interfere with shackling and bleeding. Animals are more likely to be bled incorrectly if they are rigid or kicking. When conventional head-only stunning is used, employees in slaughter plants will sometimes turn the stunner voltage down to reduce kicking. This practice may prevent the grand mal seizure and the animal may therefore be sensible during shackling and bleeding.

Cardiac arrest stunning greatly reduces or eliminates kicking, because the electricity passing through the spinal cord depolarizes spinal neurons (Gilbert et al. 1984). Practical experience with pigs and sheep indicates that a stunning time of 4 seconds will produce better stillness than will a 2 second stunning time. Good electrode contact is required for effective stillness. The electrode should be placed as close to the spine as possible. Head-to-back stunning produced better stillness in sheep than did head-to-foreleg stunning (Gilbert 1980; Gilbert et al. 1984). The stillness produced by head-to-foreleg stunning is still good. However, Gilbert and Devine (1982) report that higher currents are required to induce stillness in sheep with head-to-foreleg stunning compared to head-to-back stunning. Properly applied head-to-back, or headto-foreleg cardiac arrest stunning will produce a relaxed carcass which is easy to bleed and process.

In pigs, head-to-foreleg stunning produced good muscle relaxation and stillness in the forequarters. Observations in the United States slaughter plants indicated that replacing a small back electrode with a large saddle-shaped electrode improved stillness and the carcass was more relaxed and easier to bleed. Cardiac arrest induced by a high voltage head-only stunner often produced a stiff carcass which was more difficult to bleed correctly. One advantage of cardiac arrest stunning is that the more relaxed carcass allows for more accurate insertion of the bleeding knife. This higher accuracy will help reduce the incidence of shoulder sticks which damage the meat. A still, relaxed carcass is required in countries where edible blood is collected through a hose.

\section{Ritual Slaughter}

Recently, Moslem religious authorities have prohibited the use of cardiac arrest stunning on animals which are slaughtered in New Zealand for shipment to the Middle East. Head-only electric stunning is still per- 
mitted. To maintain adequate stillness, a current that does not stop the heart is passed through the animal after conventional head stun. The current is passed from the forelegs to the hindlegs. Stillness can be maintained by either a brief current (spinal discharge) or a continuous current (immobilization). A $200 \mathrm{~Hz} 80$ volt current applied for 5 seconds is most effective in spinal discharge method for sheep (Gilbert et al. 1984). Immobilization is accomplished by 40 volt square waves at 14.28 $\mathrm{Hz}$. A similar system has been developed for Halal (slaughter according to Moslem law) treatment of cattle. A four-second, 1.5 to $2.5 \mathrm{amp}$ head stun is applied in an automatic stunning pen, and kicking is suppressed by immobilizing the animal with a continuous 80 -volt peak, $15 \mathrm{~Hz}, 5$ msec duration square wave current (Devine et al. 1985). The Halal cut is made within 10 seconds after the head stun; before the immobilizing current is applied.

Devine et al. (1985) has tested this method in the laboratory with the EEG and determined that the cattle remained unconscious when the immobilizing current is applied. The immobilizing current appears to prolong the period of unconsciousness which is induced by the head stun. When this method was used under commercial conditions in a slaughter plant there were many serious problems (Blackmore 1985, personal communication). Blackmore states that the method can be further developed to be humane under commercial conditions.

For conventional slaughter, cardiac arrest is the most reliable electrical method to induce and maintain insensibility. Cardiac arrest stunners are simple and would probably be less likely to malfunction. If an animal regained consciousness while the immobilizing current was on, it would feel the shock and be paralyzed. However, electro-immobilization should not be used as a standard restraining method as it is aversive to conscious sheep (Grandin et al. 1985). Sheep will avoid entering a place where they have experienced electro-immobilization. Electro-immobilization was found to be more aversive than a mechanical restraining chute that squeezes and tilts the sheep to a horizontal position.

\section{Carcass Bruises}

Sheep and cattle, and to a lesser extent pigs, can still be bruised after stunning. Cattle stunned with a captive bolt can be bruised when they are rolled out of the stunning pen (Meischke and Horder 1976). In sheep, the use of cardiac arrest stunning reduced the susceptibility to bruising by 69 percent (Gregory and Wilkins 1984). The use of cardiac arrest stunning would help reduce the bruises caused by the animal's jerking shackles, falling on the floor, or striking sharp corners during the spasms which occur in the interval between conventional stunning and bleeding.

\section{Bleeding}

Livestock and poultry only lose 35 to 60 percent of the total circulating blood regardless of stunning or slaughter method (Warris 1984; Kotula 
and Helbacka 1966). Research indicates that livestock and poultry will bleed adequately after cardiac arrest stunning. Stopping the heart has no effect on shelf life of the meat, blood content in the muscle, blood pigment levels in the muscle and bacteriological levels (Chrystall et al. 1980-81; Griffiths 1983; Warris 1984; Lambooy 1981; Weise et al. 1982). In poultry, there was little correlation between the amount of blood lost during bleeding and appearance of the carcass (Newell and Shaffner 1950). There sometimes arises in poultry the problem of blood trapped in the larger vessels, which presents an unattractive appearance (Davis and Coe 1954; Newell and Shaffner 1950).

Cardiac arrest stunning applied sequentially to the head and chest of pigs with stunning tongs had no effect on the weight of the blood lost, rate of blood loss, or blood retained in the carcass (Warris and Wotton 1981). In one large pork slaughter plant, head-to-back cardiac arrest stunning caused small amounts of blood to be retained, and subsequently released into the scalding tank. There was no effect on meat quality. There was no additional blood contamination of the scalding tank caused by head-to-back cardiac arrest stunning in another plant. This plant had a well-trained person doing the bleeding and a five minute bleeding time. There were no differences in the appearance or quality of the meat compared with pigs stunned with a conventional electric stunner.

In sheep, the rate of bleeding was slower, and more blood was retained in the carcass (Kirton et al. 1980-81; Crystall et al. 1980-81). The retained blood was located in the thoracic cavity, abdominal viscera, heart and lungs (Warris 1984). This blood drains from the carcass during dressing procedures. There were no differences in meat quality between cardiac arrest and conventionally stunned sheep (Crystall et al. 198081). Cardiac arrest slowed bleeding of calves (Lambooy 1981).

Cardiac arrest stunning greatly slows the bleeding rate of poultry, but there were no significant differences in the total blood loss after 180 seconds (Weise et al. 1982; Schutt-Abraham et al. 1983). Blood loss at 90 seconds after bleeding was significantly less. Birds which had not been bled at all could not be distinguished from normally bled birds on the dressing line (Heath et al. 1981). Weise et al. (1982) found that a taste panel could detect no difference in the meat of cardiac arrest and conventionally stunned birds, and there was no adverse effect on muscle $\mathrm{pH}$, juice retention, or keeping quality.

Some people believe that a condition called "redskins" (a cherry red color widespread on the carcass) is caused by killing birds with the electric stunner. Heath et al (1983) found that redskins are probably birds which entered the scalding tank alive. Red skin carcasses are produced when live birds enter the scald tank (Griffiths and Purcell 1984). Cardiac arrest stunning would prevent this problem. Veerkamp 
and de Vries (1983) report that poultry stunned at 200 volts in a brine stunner had significantly more reddened wing tips and tails than birds stunned at 75 volts. These authors did not indicate whether or not the higher setting induced cardiac arrest. Red wing tips are caused by rupture of small blood vessels when the feathers are removed (Heath 1984b). Reddened wing tips and redskins may be caused by different physiological mechanisms.

\section{Accelerating Bleed-out}

One possible disadvantage of cardiac arrest stunning is increased BOD (biological oxygen demand) from blood in the scalding tank and losses in total blood collection. Blood has a high organic content (Harris and Carter 1977) and its presence in the plant's waste water would increase sewage treatment costs. Many poultry plants have a 60 second or less bleeding time (Harris and Carter 1977), and doubling the bleeding time would force some plants to make expensive alterations or entail the building of additions to lengthen the bleeding rail. In general, pork slaughter plants will have minimal problems and poultry plants will have the greatest problems in converting to cardiac arrest stunning. Cardiac arrest stunning is used commercially in New Zealand on sheep; the advantages of increased carcass stillness far outweigh the disadvantage of slightly slower bleed-out.

A simple electrical carcass stimulator greatly reduced scald tank contamination in one pork plant. This device shocks the carcass during bleed-out, at 16 to 32 volts at $60 \mathrm{~Hz}$. Dried blood yields in a plant with a stimulator and cardiac arrest stunning were at normal industry levels. An electrical stimulator used to tenderize and condition beef carcasses increased blood losses from the carcass (National Provisioner 1979). The use of rhythmic electrical stimulation to speed up bleeding in poultry has been suggested by Muller (1978). Stunning poultry at 480 $\mathrm{Hz}$ was found to improve bleed-out (Kuenzel et al. 1978). The use of high frequencies may make a bleed-out stimulator more effective. There is some concern that stimulating the carcass may lower meat quality in pigs by lowering muscle $\mathrm{pH}$ (Jensen et al. 1978). This would not be a problem in veal, beef, or lamb, as in these species, electrical stimulation is used to improve meat quality (Cross 1979). There have been many studies to determine the best voltage, waveform, and pulse time for electrical stimulation for tenderizing and conditioning meat (Cross 1979). Reports from the Commonwealth Scientific Industries Research Organization (CSIRO) in Australia contain information on waveform and frequency (CSIRO 1983, 1981). This information could be used as a starting point to develop inexpensive and practical bleeding rate accelerators. If excessive $\mathrm{pH}$ drop is a problem in pigs, the use of vibration may help remove the blood faster. 


\section{Bloodsplash, Speckle and Hemorrhages}

Electric stunning sometimes produces hemorrhages in the muscle, fat, and connective tissue. These hemorrhages cause economic losses as they damage the appearance of the meat. The wholesomeness of the meat is not affected except in severe cases when bloody meat is trimmed. Sometimes the damage is so severe that an entire ham or chicken may be rejected. The European pork industry may suffer greater economic losses due to hemorrhages because their pork is sold with the skin intact. In the United States, however, superficial speckling in the fat can be trimmed away. Countries and meat plants which export have greater losses due to hemorrhages because the importing country will sometimes reject or downgrade blemished meat.

Failure to distinguish between hemorrhage types may account for some conflicting reports in the literature. Bloodsplashes are hemorrhages which occur in the muscle and internal organs (Leet et al. 1977). Splashes range in size from pin heads to half an inch $(1.25 \mathrm{~cm})$. Speckle is small "salt and pepper" hemorrhages which occur in the fat and connective tissue around muscles (Thornton et al. 1979; Gilbert 1980; Petersen and Wright 1982). The biological mechanisms which cause bloodsplash and speckle may be different (Petersen and Pauli 1983).

\section{Animal Susceptibility to Hemorrhages}

There are many factors which will either increase or decrease an animal's susceptibility to hemorrhages. The stunning method is only one factor. Observations in pork and beef plants in the United States and Canada indicate an increase in the number of animals with hemorrhages in the fall and early winter when temperatures fluctuate. Hemorrhages may increase when the temperature rises after a cold spell. There is evidence that vasodilation increases the amount of speckle (Devine et al. 1983). As the season progresses from fall to winter, the susceptibility to hemorrhages decreases in lambs (Petersen and Wright 1982). Hemorrhages decrease when the temperature becomes uniformly cold. Natural causes of bloodsplash have a larger effect on bloodsplash severity than do different electric stunning methods (Kirton and Frazerhurst 1983). There is also a tendency for lambs slaughtered early in the day to have less speckle. Bloodsplash levels changed on different slaughter days (Kirton and Frazerhurst 1983). A Danish study indicated bloodsplashing levels in pigs were not affected by holding time in the stockyards, sugar feeding, and type of truck used to transport pigs (Nielson 1977). Observations in the United States and Canada indicate that resting animals before slaughter may reduce hemorrhages, as livestock are transported much greater distances in North America.

There are also differences in hemorrhage susceptibility among groups of animals. For example, sheep from some farms had more blood- 
splash than sheep from other farms (Pearson et al. 1977), and lambs that ate coumarin (anticoagulant) producing plants had more bloodsplash (Restall 1980-81). There also may be genetic factors to consider as pigs from different regions or countries may be hemorrhage resistant or hemorrhage prone. Large, heavily-muscled pigs have a tendency to have more hemorrhages and fractures. Younger animals may also be more susceptible (Thornton et al. 1979).

\section{Stunning Method Effects}

While captive bolt and $\mathrm{CO}_{2}$ stunning usually produce less hemorrhages compared to electric stunning (Larsen 1983; Blackmore 1983), problems with these systems do exist. For example, concerns about the humaneness of the use of $\mathrm{CO}_{2}$ for slaughter have been expressed (Hoenderken 1978; Grandin 1980a). Regarding the captive bolt, this method has a detrimental effect on meat quality in pigs, and therefore, electric stunning is the preferred method (Grandin 1980d; Overstreet et al. 1975). In sheep and calves, electric stunning is more economical and the brains (a consumer product) are not contaminated by a penetrating captive bolt. The nonpenetrating captive bolt which does not contaminate the brains, induces insensibility in only 80 to 95 percent of lambs according to Blackmore (1983), and unless this system is improved, it is not to be considered acceptable for lambs or sheep.

Cardiac arrest stunning produces less bloodsplash in the muscle compared to conventional electric stunning (Kirton et al. 1980-81; Gilbert and Devine 1982; Gilbert 1980). Bloodsplash is reduced because heart stoppage prevents a blood pressure rise after the stunning (Kirton et al. 1980-81). It appears, however, that blood pressure changes during stunning do not influence the amount of speckle (Gilbert and Devine 1982). Gilbert and Devine (1982) report that head-to-back stunning has minimal bloodsplash but will produce speckling in lambs. Head-toforeleg cardiac arrest stunning was found to be the best method as it produced less speckle and bloodsplash than either head-only or head-toback cardiac arrest in sheep (Gilbert 1980; Gilbert and Devine 1982). Head-to-back leg application of the stunner will produce more speckling than will head-to-foreleg application when the lambs are held in a V-conveyor restrainer (Blackmore and Petersen 1981). Shortening the distance between the electrodes on a head-to-back stunner reduced speckle in lambs; a span of ten inches $(26 \mathrm{~cm})$ was found to produce better results than 13.5 inches $(34 \mathrm{~cm}$ ) (Petersen and Wright 1982). The spring-loaded foreleg electrode must remain in firm contact with the legs as making and breaking the contact may increase bloodsplash and speckle. 


\section{Effect of Restrainer}

The type of restrainer used to hold the animal during stunning can affect the amount of bloodsplash and speckle. A V-conveyor restrainer with a steep angle of 15 degrees from vertical on each side caused greater amounts of speckle than did a restrainer with the conveyors on a 55 degree angle (Thornton et al. 1979). An electrode position and stunner setting which causes speckle in a V-conveyor restrainer may not cause speckle in some other type of restrainer such as the double rail, or stunning without a restrainer.

When sheep were restrained in a hammock, head-to-back cardiac arrest stunning produced no bloodsplash or speckle, and conventional head-only stunning produced lesions in 10 percent of the animals (Gregory and Wotton 1984d). Observations by Mattson (1984, personal communication) of the Swedish Meat Research Institute indicated that pigs stunned on the floor had fewer hemorrhages. However, accurate placement of the stunner is more difficult when the animals are on the floor, and pigs stunned in such a manner are also more likely to have broken shoulders (Van der Wal 1976).

Human activities may also affect carcass quality. For example, observations in a pork slaughter plant indicated that more bone compression fractures occurred after lunch and coffee breaks. This was probably due to the animals being left in the restrainer. Observations with electrically stunned calves indicated that shortening the period of time the animal remains in the restrainer may reduce hemorrhages. It is the author's opinion that the effect of the restrainer on hemorrhages is not caused by adrenalin secretion or psychological stress, as I have observed pigs sleeping in the restrainer during lunch. Injections of adrenalin do not cause speckle (Gilbert 1980). The increase in homorrhages is due to the skin being stretched just before or during stunning when the animal moves against the side of the restrainer (Gilbert and Devine 1982). In a pork plant, bloodsplash and speckle increased when one side of the restrainer conveyor was broken and the animals' rubbing against the immobile conveyor stretched the skin and muscles. Excitement is likely to cause speckle because an excited animal will struggle and fight the restrainer. Mechanical stretching of the skin and muscle and opposing muscle groups interacting with each other during tonic contracture at stunning is believed to be a cause of speckle (Gilbert and Devine 1982).

The V-conveyor restrainer is an excellent system for the humane handling of animals. All livestock except baby calves will enter the restrainer easily and ride in it with a minimum of excitement. Restrainer induced speckle can be greatly reduced by using head-to-foreleg stunning, changing the angle of the conveyors, and removing the animals from the restrainer when the slaughter line is stopped. The use of the 
double rail restrainer (Giger et al. 1977) and new restrainer designs should be investigated. The use of a squeeze restrainer may help to reduce hemorrhages in smaller plants. This restrainer holds a pig for only a few seconds between two padded panels.. This system requires less space than a V-conveyor restrainer and it can handle up to 300 pigs per hour.

\section{Stunning Time, Voltage Amperage and Frequency Effects}

Shortening the interval between electric stunning and bleeding will help prevent hemorrhages in pigs and sheep (Warrington 1974; Burson et al. 1983; Calkins et al. 1980; Van der Wal 1978). L. Davey, Meat Research Institute of New Zealand, stated that bleeding sheep within 8 seconds after removal of the stunner greatly reduced hemorrhages. Practical experience indicates that when a voltage regulated stunner is used, the number of compression fractures and severe hemorrhaging in the hams of pigs is increased when the voltage was raised. In lambs, long stunning times and higher currents produced more speckle in the leg muscles with a head-to-back cardiac arrest stunner than did short stunning times and lower currents (Devine et al. 1983). In pigs longer stunning times of 12 seconds with 320 volt $50 \mathrm{~Hz}$ head-only stunning produced more hemorrhages and broken bones than did a 2 second time (Braathen and Johansen 1984). The use of constant current stunners would help prevent hemorrhages because high current surges would be eliminated. A Danish study on pigs indicated that 700 volt headonly stunning in an automatic system greatly reduced shoulder hemorrhages compared to a 300 volt manual head-only stunning (Larsen 1983). The 700 volt system induced cardiac arrest in many of the pigs. Stunning times were not given but the 700 volt automatic system usually has a shorter stunning time than does a 300 volt manual. The incidence of fractures in both systems was approximately 1 percent.

Increasing the voltage in a poultry stunner greatly increases the number of birds damaged by hemorrhages in the wing joints and broken bones according to $\mathrm{R}$. Lewis Wesley, Virginia State University (personal communication, 1984). Stephen Pretanik, Director of Science and Technology, National Broiler Council (personal communication, 1985) also states that "When electric stunners are set at a level sufficient to kill the bird, considerable internal damage is caused to the bird." Some examples of the damage are broken bones, and bloody areas in the meat and joints. Turkeys have severe contusions of the breast muscles and bloodsplash if the amperage is too high (Howard Hunter 1984, personal communication). Wesley (personal communication, 1984) states that damage can be prevented by conventional stunning at less than 40 
volts at high frequency for 7 seconds. Kuenzel and Walther (1978) recommend $480 \mathrm{~Hz}$. There is a need for research to verify that this method of conventional stunning induces unconsciousness. According to Kuenzel and Walther (1978) a peak voltage of 100 volts, average voltage of 30 volts at $480 \mathrm{~Hz}$ is required.

\section{Electric Prods}

The use of electric prods to drive animals may increase bloodsplash and speckle. Calkins et al. (1980) found that pigs driven with an electric prod had almost twice as many hemorrhages compared with pigs driven with a leather strap. The exact specifications of the prods was not known, but they were either connected to a transformer which stepped down the voltage from 120 volts $\mathrm{AC} 60 \mathrm{~Hz}$, or they had a small light bulb wired in series to serve as a resistor. Although it is illegal to connect prods directly to the house current without a transformer, some plants still engage in this practice. Observations in Europe indicated that it was difficult to induce hemorrhages by prodding pigs in the leadup chute with a battery operated electric prod (Lambooy 1984, personal communication). A prod wired to a transformer has only a single contact and the electricity flows through the animal to the ground. This causes muscles to tense up. A battery prod has two contacts and the electric shock is localized. Pork plants with electric prods wired through a transformer found they could reduce hemorrhages and broken aitch (hip) bones by lowering prod voltage to $14-16$ volts.

\section{Shackle Jerking and Leg Movement}

Jerking the leg of a stunned animal by the shackle chain can cause blood vessels to break in the ham. Sometimes hemorrhage problems caused by the jerking of shackle chains are blamed on the stunning method. Systems for conveying the stunned pig should be designed to lift it up smoothly without jerking the shackled leg. The animal's legs must be able to move freely during the spasm which occurs during stunning, otherwise, broken aitch bones and hemorrhages will result if the animal's feet hit an obstruction under the restrainer. Beveling the edges of the restrainer slats at the point where the legs contact may enable the legs to slide more freely during the spasm.

\section{PSE and Electric Stunning}

Stunning and slaughter methods can affect the incidence of PSE (pale soft exudative) meat in pigs (Grandin 1980d); Athen et al. 1977; 
Larsen 1983). This condition lowers meat quality in pork (Grandin 1980d; Van der Wal 1978), but rarely causes meat quality problems in lambs, calves, or cattle. Shortening the stunner application time from 12 seconds to 2 seconds reduced PSE (Braathen and Johansen 1984; Marple 1977; Van der Wal 1978), because shorter application times have less of an effect on muscle $\mathrm{pH}$ (Devine et al. 1984). In sheep, head-only stunning produced a smaller drop in muscle $\mathrm{pH}$ than head-to-backcardiac arrest stunning (Devine et al. 1984; Petersen and Blackmore 1982). In pigs, a lower muscle $\mathrm{pH}$ is usually related to increased PSE.

A Danish study in pigs indicated that 700 volt head-only automatic stunning caused slightly less PSE than 300 volt head-only manual stunning (Larsen 1983). The 700 volt stunner induced cardiac arrest in many pigs. A Dutch study by Van der Wal et al. (1983) with similar equipment showed a tendency for the 700 volt stunned pigs to have a lower $\mathrm{pH}$ and higher carcass temperature. The conflicting results are probably due to differences in the methods for measuring PSE or confounding of the Dutch trial by carcass grade. PSE measurements with an optical probe and $\mathrm{pH}$ sometimes give different results (Larsen 1983).

Swatland (personal communication, 1984), and Van der Wal (1978) state that kicking and muscular contractions after stunning increases PSE. Pigs kick violently after conventional stunning. The use of cardiac arrest stunning with a short application time may help reduce PSE because damaging heat buildup in the muscles caused by kicking would not occur. Pigs kick more violently after conventional stunning than do sheep, and heat buildup may occur more quickly due to the heavy layer of insulating fat. Practical experience in large North American slaughter plants indicates that shortening the interval between stunning and bleeding helped reduce PSE.

\section{Other PSE Factors}

There are many causes of PSE which have a greater influence on its incidence than do differences in electrical stunning methods. PSE is a complex condition which is caused by the interaction of many different factors (Grandin 1984; Canadian Meat Council 1980; Eikelenboom 1984). One of the most important factors is genetic stress susceptibility or PSS (porcine stress syndrome) as evidenced by the fact that different pig breeds and strains within a breed or crossbreed have different levels of PSS (Tarrant et al. 1979; Eikelenboom 1984).

Other factors may affect PSE incidence as well. Fluctuating temperatures and unstable weather conditions may double the incidence of PSE. Handling at the slaughter plant is very important also. Welldesigned chutes are essential, as is the proper human handling (Grandin 1982,1985 ). If they become excited in the chute leading to the stunner, normally stress-resistant pigs will have more PSE and lower meat 
quality (Barton-Gade 1984). Observations in packing plants indicate that gentle handling in the stunning chute reduces PSE. Showering pigs in the stockyards helped reduce PSE mainly by lowering body temperature (Smulders et al. 1983). In another study, showering had no effect on PSE incidence during cold weather (Mattson 1984, personal communication). These findings illustrate the importance of keeping pigs cool and avoiding overheating. A short, four-hour rest period after arrival at the slaughter plant is beneficial for meat quality (Malmfors 1982). Observations in North American slaughter plants indicate that slaughtering pigs immediately after arrival at the plant is detrimental to meat quality.

A basic principle is that a long-term stress tends to make meat darker and drier than normal and a short-term stress tends to increase PSE (Nielson 1977; Grandin 1980d). Pigs which have been on a long truck ride often have a lower incidence of PSE (Grandin 1980d). Longhaul pigs have less PSE because glycogen (muscle fuel) is exhausted.

There are unknown factors which determine the incidence of PSE. There are some exceptions to the short-term and long-term stress principle. Breeds or strains of pigs that are more excitable may have high levels of PSE after a long truck ride. Fatigued cattle sometimes have a PSE-like condition after electrical stimulation of the carcass (FjelknerModig and Ruderus 1983). A similar condition may exist in electrically stunned fatigued pigs. Some of the confliciting data is due to the possibility that there are different kinds of PSE with different physiological mechanisms (Monin and Sellier 1985; Grandin 1984). Monin and Sellier (1985) found that normal stress-resistant pigs of the Hampshire breed often have inferior meat quality. This breed of pig has higher levels of glycogen. Different measuring methods might provide different readings in genetically stress-susceptible and normal pigs (Barton 1984, personal communication).

\section{Conclusions}

Cardiac arrest stunning is definitely recommended for the humane stunning of hogs, sheep, and calves. To induce instantaneous unconsciousness, the electric current must pass through the brain. Humane cardiac arrest stunning can be accomplished by placing the positive electrode on the animal's head and the ground electrode may contact the back, forelegs, hindlegs, brisket, or groin. Another cardiac arrest stunning method is to pass a current through the head first. A second current is then passed through the heart.

Sufficient amperage must be applied to cause unconsciousness. Minimum amperage settings for wet animals with good electrode contact 
are: market hogs, 1.25; calves, 1.25; shorn lambs, 0.75 . Higher settings may be needed to induce unconsciousness if animals are old, dehydrated, have long hair or wool, heavy backfat, or dry hair or wool. There are many variables which will change amperage requirements. Amperage settings higher than these minimums will be required in many slaughter plants.

\section{Author's Addendum}

\section{Is Electro-Immobilization Humane? A Review of Recent Studies}

There have been concerns about the humaneness of electroimmobilization of livestock. Battery-operated electro-immobilizers have been developed to restrain cattle for veterinary procedures such as dehorning, and sheep for shearing. The devices immobilize the animals by passing a small electrical current through their bodies. The animal is held rigid by contractions of its muscles. The manufacturers of these devices claim that immobilization relieves pain and is less stressful than are conventional mechanical restraints such as squeeze chutes.

Two different research laboratories have found that electro-immobilization does not block the sensation of pain. Animals will react to painful stimuli while they are immobilized (Lambooy and van Voorst 1983; Lambooy 1985). Amend (1983) states that there is no reliable evidence that electro-immobilization is a pain reliever. Studies with the EEG in calves and sheep indicate that electro-immobilization does not induce electro-anesthesia or electro-sleep (Lambooy and van Vorst 1983). The animals remain sensible during electro-immobilization.

Research conducted by Grandin, Curtis, Widoski and Thurmon (1985) indicates that electro-immobilization is more aversive (disliked) than is restraint in a squeeze tilt table. In a choice test, sheep preferred to be restrained in the squeeze tilt table. The choice tests were conducted in a specially designed sheep handling facility. It had a Y-chute which led to either an electro-immobilizer or to a squeeze tilt table which tilted the sheep to a horizontal position. Each animal was given several choice tests. Ewes which made a choice were rewarded with grain after they were immobilized or restrained in the squeeze tilt table. Ewes that refused to make a choice within five minutes were released. They were not given a grain reward.

Three different commercially available electro-immobilizers were tested. The sheep's choices in three different trials were: electroimmobilizer 13 percent, 13 percent, and 8 percent respectively; squeeze tilt table 79 percent, 57 percent, and 71 percent; and no choice 8 percent, 30 percent, and 21 percent. Ninety-four percent of the sheep chose the squeeze tilt table again after experiencing it once, but 56 percent of the sheep never chose the electro-immobilizer again after experiencing it once. 
The sheep became less willing to enter the handling facility after they had experienced both the electro-immobilizer and the squeeze tilt table. Some sheep had to be grabbed and forced into the chute. Electroimmobilization also reduced the sheeps' acceptance of a feed reward. All of the sheep which chose the squeeze tilt table accepted the grain reward, but many of the sheep that were electro-immobilized either refused the reward or only took one bite.

The day after the choice tests were conducted, many of the sheep were still reluctant to enter the handling facility. Gradually the sheep were coaxed into the chute with a bucket of grain and put in the squeeze tilt table. As experience with the tilt table only increased, the sheep became progressively more willing to enter the table for the grain reward. Some animals entered the squeeze tilt table repeatedly and were willing to be squeezed and tilted for the grain reward.

A study by Pascoe and McDonnel (1985) also indicated that electroimmobilization was aversive. They trained Holstein cows to enter a set of stocks. The cows were subjected to four different treatments in the stocks. The treatments were: control (held in the stocks only), saline injection, immobilizer low setting, and immobilizer high setting. These treatments were repeated ten times. Cattle which had been immobilized became more reluctant to enter the stocks. They had higher heart rates upon entering than the controls or the cows which received the saline injection. The immobilized cows also showed a more pronounced emotional reaction before they received the shock. The authors concluded that electro-immobilization was painful.

Carter et al. (1983) reports that one-third of the cattle bellowed when the immobilizer current was turned on. I tried putting all three commercially available immobilizers on my own forearm. The sensation felt like getting a shock, and it was very disagreeable. The sensation was similar at both high and low settings. Different people have reported different reactions to placing the immobilizers on themselves, from a thudding sensation to a very painful one. It is likely that different people and animals may react differently. In sheep and calves, there are large individual differences in the amount of current required to maintain immobilization (Lambooy and van Voorst 1983). Some animals required almost twice as much current.

Carter et al. (1983) measured cortisol (stress hormone) levels in cattle after they were dehorned. There were three different groups: immobilized during dehorning, no immobilization during dehorning, and local anesthetic prior to dehorning. There were no significant differences in the cortisol levels between the three groups. The local anesthetic group may have failed to have lower cortisol levels because they had been handled four times. The other two groups were handled only twice. It is likely that dehorning is such a painful experience that the cortisol 
levels reached maximum levels in both the immobilized and nonimmobilized cattle. More recent research by Lambooy (1985) indicated that electro-immobilization is stressful. The pulse rate and plasma cortisol level increased greatly during current administration in calves, sheep, and pigs. Lambooy (1985) concludes, "Because of the dubious effects on the animal's welfare, the use of such an apparatus (Feenix Stockstill ${ }^{\mathrm{TM}}$ ) cannot be recommended."

For animal welfare reasons, I do not recommend electro-immobilization for routine husbandry procedures such as shearing, dehorning, or castration. A good sturdy squeeze chute is recommended for cattle. Electro-immobilization must never be used as a substitute for anesthetics during major surgery (Pascoe, personal communication). 


\section{References}

Agricultural and Food Research Council. 1984. A practical guide to neck cutting in poultry. MRI Memorandum No. 54. Meat Research Institute. Langford, Bristol, England.

Amend, J.F. 1983. Preliminary verdict for electro-immobilization. Int. J. Study of Anim. Probs. 4:11-13

Athen, T.G., Ono, K. and Topel, D.G. 1944. Effect of stress susceptibility or stunning method on catecholamine levels in swine. Journal of Animal Science. 44:985-9

Baldwin, B.A. 1971. Anatomical and physiological factors involved in slaughter by carotid section, In: Humane Killing and Slaughterhouse Techniques. Universities Federation for Animal Welfare. Potters Bar, Hert, England. pp. 34-43.

Barton-Gade, P. 1984. Influence of halothane genotype on meat quality in pigs and subjected to various pre-slaughter treatments. 30th European Meeting of Meat Research Workers Proceedings. Bristol, England. 1:3 pp. 8-9.

Blackmore, D.K. 1983. Problems associated with percussion stunning in sheep. In: Stunning of Animals for Slaughter. Eikelenboom, G., ed. Boston: Martinus Nijhoff. pp. 146-53.

Blackmore, D.K. 1984. Differences in behaviour between sheep and cattle during slaughter. Res. Vet. Sci. 37:223-6.

Blackmore, D.K. and Newhook, J.C. 1981. Insensibility during slaughter of pigs in comparison to other domestic stock. New Zealand Vet. J. 29:219-2.

Blackmore, D.K. and Petersen, G.V. 1981. Stunning and slaughter of sheep and calves in New Zealand. New Zealand Vet. J. 29:99-102.

Blackmore, D.K. and Newhook, J.C. 1983. The assessment of insensibility in sheep, calves and pigs during slaughter. In: Stunning of Animals for Slaughter. Eikelenboom, G. ed. Boston: Martinus Nijhoff. pp. 13-25.

Blackmore, D.K., Newhook, J.C. and Grandin, T. 1983. Time of onset of insensibility in four- to six-week old calves during slaughter. Meat Sci. 9:145-9.

Braathen, O.S. and Johansen, J. 1984. The effects of short or long electrical stunning times on pork quality. 30th European Meeting of Meat Research Workers Proceedings. Bristol, England. pp. 22-23.

Burson, D.E., Hunt, M.C., Schafer, D.E., Beckwith, D. and Garrison, J.R. 1983. Effects of stunning method and time interval from stunning to exsanguination on blood splashing in pork. J. Anim. Sci. 57:918-21.

Calkins, C.R., Davis, G.W., Cole, A.B. and Hutsell, D.A. 1980. Incidence of blood splashed hams from hogs subjected to certain antemortem handling methods. J. Anim. Sci. 50:15 Supplement A (Abstract).

Canadian Meat Council. 1980. Guide to PSE Pork. Canadian Meat Council, Islington, Ontario, Canada.

Carter, P.D., Johnston, N.E., Corner, L.A. and Jarrett, R.G. 1983. Observations on the effect of electro-immobilization on the dehorning of cattle. Austral. Vet. J. 60:17-19.

Chambers, R.M. 1963. Operator performance in acceleration environments. In: Unusual Environments and Human Behavior. Burns, N.M., Chambers, R.M. and Hendler, E. eds. London: Free Press of Glencoe.

Chrystall, B.B., Devine, C.E. and Newton, K.G. 1980-81. Residual blood in lamb muscles. Meat Sci. 5:339-45.

Croft, P.S. 1952. Problems of electrical stunning. Vet. Rec. 64:255-8.

Croft, P.G. and Hume, C.W. 1956. Electric stunning of sheep. Vet. Rec. May 26. pp. 318-21.

Cross, H.R. 1979. Effect of electrical stimulation on meat tissues and muscle properties: A review. J. Food Sci. 44:509-23.

CSIRO. 1981. Effective electrical stimulation of beef carcasses and sides. No. 81/5. 1981. CSIRO Division of Food Research. Brisbane, Australia.

CSIRO. 1983. Effective extra low voltage electrical stimulation of beef-What you need to know. Meat Research Newsletter. Vol. 5 (September 26). CSIRO Div. of Food Research. Brisbane, Australia. 
Daly, C.C. 1985 . Visually evoked responses during slaughter. Vet. Rec. (Letters to the Editor). May 25, 1985. pp. 574-5.

Davis, L.L. and Coe, M.E. 1954. Bleeding of chickens during killing operations. Poultry Sci. 33:616-9.

Devine, C.E., Gilbert, K.V. and Ellery, S. 1983. Electrical stunning of lambs: The effect of stunning parameters and drugs affecting blood flow and behavior on petechial hemorrhage incidence. Meat Sci. 9:247-56.

Devine, C.E., Ellery, S., Wade, L. and Chrystall, B.B. 1984. Differential effects of electrical stunning on the early post-mortem glycolysis in sheep. Meat Sci. 11:301-9.

Devine, C.E., Gilbert, K.V., Tavener, A. and Day, A. 1985. The use of electrical stunning followed by electro-immobilization for the humane slaughter of cattle. New Zealand Veterinary Journal. 33:47.

Duane, T.D. 1954. Observations on the fundus oculi during blackout. AMA Archives of Opthalmology 51:343-55.

Eikelenboom, G. 1984. An overview of PSE in Europe. Proceedings 64th Annual Conference. Canadian Meat Council, Islington, Ontario. Paper 9-1.

Fjelkner-Modig, S. and Ruderus, H. 1983. The influence of exhaustion and electrical stimulation on the meat quality of young bulls: Part I-Post mortem $\mathrm{pH}$ and temperature. Meat Sci. 8:185-201.

Fraser, T.M. 1973. Sustained linear acceleration. Parker, J.F. and West, V.R. eds. Bioastronautics Data Book. 2nd edition. Scientific and Technical Information Office, NASA. Washington, D.C.

Frazerhurst, L.F. 1975. Interim report on current developments in electrical stunning of sheep and lambs. Meat Research Institute of New Zealand, MIRINZ. 442:1-9.

Giger, W., Prince, R.P., Westervelt, R.G. and Kinsman, D.M. 1977. Equipment for low-stress animal slaughter. Transactions of ASAE. 20:571-8.

Gilbert, K.V. 1980. Developments in stunning and slaughter. 21st Meat Industry Conference. MIRINZ. Hamilton, New Zealand. pp. 18-25.

Gilbert, K.V. and Devine, C.E. 1982. Effect of electrical stunning method on petechial hemorrhages and on the blood pressure of lambs. Meat Sci. 7:197-207.

Gilbert, K.V., Devine, C.E., Hand, R. and Ellery, S. 1984. Electrical stunning and stillness of lambs. Meat Sci. 11:45-58.

Grandin, T. 1980a. Mechanical, electrical and anesthetic stunning methods for livestock. Int. J. Study Anim. Probs. 1:242-63.

Grandin, T. 1980b. Is your hog stunner insulated? Meat Processing. February: 69.

Grandin, T. 1980c. Designs and specifications for livestock handling equipment in slaughter plants. Int. J. Study Anim. Probs. 1:178-200.

Grandin, T. 1980d. The effect of stress on livestock and meat quality prior to and during slaughter. Int. J. Study Anim. Probs. 1:313-37.

Grandin, T. 1980e. Problems with kosher slaughter. Int. J. Study Anim. Probs. 16:375-90.

Grandin, T. 1982. Pig behavior studies applied to slaughter plant design. Applied Anim. Ethol. 9:141-51.

Grandin, T. 1984. Reducing PSE losses. Meat Processing. 23(3):53,56.

Grandin, T. 1985. How to design hog chutes. Meat Processing. May.

Grandin, T., Curtis, S.E., Widowski, T. and Thurmon, J.C. 1985. Aversiveness of restraint by electro-immobilization or in squeeze tilt table. Journal of Anim. Sci. Suppl. (Abstract). 61:213-14.

Gregory, N.G. and Wilkins, L.J. 1984. Effect of cardiac arrest on susceptibility to carcass bruising in sheep. J. Sci. Food Agric. 35:671-6.

Gregory, N.G. and Wotton, S.B. 1984a. Sheep slaughtering procedures. II. Time to loss of brain responsiveness after exsanguination or cardiac arrest. British Vet. J. 140:354-60.

Gregory, N.G. and Wotton, S.B. 1984b. Time of loss of brain responsiveness following exsanguination in calves. Res. in Vet. Sci. 37:141-3. 
Gregory, N.G. and Wotton, S.B., 1984c. Sheep slaughtering procedures. I. Survey of abattoir practice. British Vet. J. 140:281-6.

Gregory, N.G. and Wotton, S.B. 1984d. Sheep slaughtering procedures. III. Head-to-back electrical stunning. British Vet. J. 140:570-5.

Gregory, N.G. and Wotton, S.B. 1985. Poultry slaughtering procedures. Paper \#2-18. European Meeting of Meat Research Workers. Albena, Bulgaria. pp. 87-91.

Gregory, N.G., Wotton, S.B. and Wilkins, L.J. 1984. The effects of inducing cardiac arrest at stunning on brain function, bleeding efficiency and susceptibility to bruising in sheep. Paper 1:13, Proceedings 30th European Meeting of Meat Research Workers. Bristol, England. pp. 25-26.

Griffiths, G.L. 1983. Proceedings of Technical Sessions World's Poultry Science Assn. Adelaide, Australia.

Griffiths, G.L. and Purcell, D.A. 1984. A survey of slaughter procedures used in chicken processing plants. Aust. Vet. J. 61:399-401.

Harris, C.E. and Carter, T.A. 1977. Broiler blood losses with manual and mechanical killers. Poultry Sci. 56:1827-31.

Heath, D. and Williams, D.R. 1977. Man at High Altitude. London: Churchill Livingstone.

Heath, G.B.S. 1984a. Slaughter of broilers. Vet. Rec. 115:98-100.

Heath, G.B.S. 1984b. The slaughter of broiler chickens. World's Poultry Sci. J. 40:151-9.

Heath, G.B.S., Watt, D.J., Waite, P.R. and Ormond, J.M. 1981. Observations of poultry slaughter. Vet. Rec. J. 108:97-99.

Heath, G.B.S., Watt, D.J., Waite, P.R. and Meakings, P.A. 1983. Further observations on the slaughter of poultry. British Vet. J. 139:285-90.

Hoenderken, R. 1978a. Electrical stunning of pigs for slaughter. Why? Hearing on Preslaughter Stunning. Kavlinge, Sweden. May 19, 1978.

Hoenderken, R. 1978b. Electrical stunning of slaughter pigs. Thesis, State University. Utrecht, The Netherlands.

Hoenderken, R. 1983. Electrical and carbon dioxide stunning of pigs for slaughter. In: Eikelenboom, G. ed. Stunning of Animals for Slaughter. Boston: Martinus Nijhoff. pp. 59-63.

Jensen, J.H., Jul, M. and Zirck, O. 1978. Electrical stimulation of pig carcasses. International Congress of Food Science and Technology Abstracts. p. 124.

Kirton, A.H. and Frazerhurst, L.F. 1983. Effects of normal, light normal or double stunning on the incidence and severity of bloodsplash in lambs. Meat Sci. 9:1-6.

Kirton, A.H., Frazerhust, L.F., Woods, E.G. and Chrystall, B.B. 1980-81. Effect of electrical stunning method and cardiac arrest on bleeding efficiency, residual blood and bloodsplash in lambs. Meat Sci. 5:347-53.

Kotula, A.W. and Helbacka, N.V. 1966. Blood volume of live chickens and the influence of slaughter technique on blood loss. Poultry Sci. 45:684-8.

Kuenzel, W.J., Ingling, A.L., Denbow, M.D., Walther, J.H. and Schaeffer, M.M. 1978. Variable frequency stunning and the comparison of two bleed-out time intervals for maximizing blood release in processed poultry. Poultry Sci. 57:449-54.

Kuenzel, W.J. and Walther, J.H. 1978. Heart beat, blood pressure, respiration and brain waves of broilers as affected by electrical stunning and bleed-out. Poultry Sci. 57:655-9.

Kuenzel, W.J. (no date) Stunning, killing and bleeding: Specifications, carcass quality and welfare concerns. pp. 63-66.

Lambooy, E. 1981. Electrical stunning and meat quality of veal calves. 27th European Meeting of Meat Research Workers, Proceedings. Vienna, Austria, August 24-28, pp. 196-7.

Lambooy, E. 1982. Electrical stunning of sheep. Meat Sci. 6:123-35.

Lambooy, E. and Spanjaard, W. 1982. Electrical stunning of veal calves. Meat Sci. 6:15-25.

Lambooy, E. 1985. Electro-anesthesia or electroimmobilization of calves, sheep, and pigs by the Feenix Stockstill. The Vet. Quart. 7:120-6.

Lambooy, E. and Van Voorst, N. 1985. Electro-anesthesia of calves and sheep. In: Eikelenboom, G. ed. Stunning of Animals for Slaughter. Boston: Martinus Nijhoff. pp. 117-23. 
Larsen, K.H. 1983. Comparison of 300 volt manual stunning, 700 volt automatic stunning and $\mathrm{CO}_{2}$ compact stunning with respect to quality parameters, blood splashing, fractures and meat quality, In: Eikelenboom, G. ed. Stunning of Animals for Slaughter. Boston: Martinus Nijhoff. pp. 73-81.

Leach, T.M. 1978. Pre-slaughter stunning in the E.C. In: Fabiansson, ed. Hearing on Pre-slaughter Stunning. Kavlinge, Sweden: Swedish Meat Research Centre.

Leet, N.G., Devine, C.E. and Gavey, A.B. 1977. The histology of blood splash in lamb. Meat Sci. 1:229-34.

Levinger, I.M. 1979. Jewish method of slaughtering animals for food and its influence on blood supply to the brain and on the normal functioning of the nervous system. Animal Reg. Studies. 2:111-26.

Lopes da Silva, F.H. 1983. The assessment of unconsciousness: General and practical aspects. In: Eikelenboom, G. ed. Stunning of Animals for Slaughter. Boston: Martinus Nijhoff: pp. 3-12.

Malmfors, G. 1982. Studies on some factors affecting pig meat quality. 28th European Meeting of Meat Research Workers Proceedings. Madrid, Spain. pp. 21-23.

Marple, D.M. 1977. The effect of slaughter and stunning methods on meat quality. Proceedings of the Meat Industry Research Conference. Auburn University, Auburn, Alabama. pp. 141-6.

Meischke, H.R.C. and Horder, J.C. 1976. A knocking box effect on bruising cattle. Food Tech. Australia. 18:369-71.

Monin, G. and Sellier, P. 1985. Pork of low technological quality with a normal rate of muscle $\mathrm{pH}$ fall in the immediate post-mortem period: The case of the Hampshire breed. Meat Sci. 13:49-63.

Muller, A. 1978. Stunning fowl. Hearing on Pre-slaughter Stunning. Kavlinge, Sweden. May 19th.

Nangeroni, L.I. and Kennet, P.D. 1963. An electroencephalographic study of the effects of Sechita slaughter on cortical function in ruminants. Report. Ithaca University, Ithaca, New York.

National Provisioner. 1979. Texas firm announces commercial electro-stimulation tenderizing. January 6, 1979. pp. 8-34.

Neilson, N.J. 1977. The influence of pre-slaughter treatment on meat quality of pigs. NJF Symposium, Muscle Function and Porcine Meat Quality. Hindsgavl, Denmark. Aug. 28th.

Newell, G.W. and Shaffner, C.S. 1950. Blood loss by chickens during killing. Poultry Sci. 29:271-5.

Newhook, J.C. and Blackmore, D.K. 1982. Electroencephalographic studies of stunning and slaughter of sheep and calves: Part 1-The onset of permanent insensibility in sheep during slaughter. Meat Sci. 6:295-300.

Overstreet, J.W., Marple, D.N., Huffman, D.L. and Nachreiner, R.F. 1975. Effect of stunning methods on porcine muscle glycolosis. J. Anim. Sci. 41:1014-20.

Pascoe, P.J. and McDonnell, W.N. 1985. Aversive conditioning used to test the humaneness of a commercial electro-immobilization unit in cattle. Vet. Surg. 14:75-76.

Pearson, A.M., Kilgour, R., de Langen, M. and Payne, E. 1977. Hormonal responses of lambs to trucking, handling and electric stunning proceedings. New Zealand Soc. Animal Production. 37:243-8.

Petersen, G.V. and Wright, D.R. 1982. Observations of subcutaneous hemorrhagic speckling in lambs. New Zealand Vet. J. 27:166-8.

Petersen, G.V. and Blackmore, D.K. 1982. The effect of different slaughter methods on the postmortem glycolysis of muscle in lambs. New Zealand Vet. J. 30:195-8.

Petersen, G.V. and Pauli, J.V. 1983. One stage prothrombin times and subcutaneous hemorrhagic speckling in lambs. New Zealand Vet. J. 31:4-6

Regensburger, R.W. 1940. Hog Stunning Pen. U.S. Patent No. 2,185,949, Washington, D.C. 
Restall, D.J. 1980-81. Blood splash in lambs-A preliminary study using the one stage prothrombin time test. Meat Sci. 5:125-9.

Richards, S.A. and Sykes, A.H., 1967. Physiological effects of electrical stunning and venesection in the fowl. Res. Vet. Sci. 8:361-8.

Roberts, T.D.M. 1954. Cortical activity in electrocuted dogs. Vet. Rec. 66:561-7.

Schulze, W., Schulze-Petzold, H., Hazem, A.S. and Gross, R. 1978. Deutche Tierarztliche Wochenschrift. 85:41-76.

Schutt-Abraham, I., Wormuth, H.J. and Fessel, J. 1983. Electrical stunning of poultry in view of animal welfare and meat production. In: Eikelenboom, G. ed. Stunning of Animals for Slaughter. Boston: Martinus Nijhoff. pp. 187-96.

Smulders, F.J.M., Romme, A.M.C.S., Woolthuis, C.H.J., de Kruijf, J.M., Eikelenboom, G. and Corstiaensen, G.P. 1983. Pre-stunning treatment during lairage and pork quality. In: Eikelenboom, G. ed. Stunning of Animals for Slaughter. Boston: Martinus Nijhoff. pp. $90-95$.

Spanjaard, W. 1981. Automatishce bedwelming/elektrocutic. G.J. Nijhuis b.v., Winterswijk, Holland.

Swatland, H.J., Brogna, R.J. and Lutte, G.H. 1984. Electrical activity in the cerebral hemispheres of electrically stunned pigs. J. Animal Sci. 58:68-74.

Tarrant, P.V., Gallwey, W.J. and McGloughlin, P. 1979. Carcass $\mathrm{pH}$ values in Irish Landrace and Large White pigs. Irish J. Agric. Res. 18:167-72.

Thornton, R.N., Blackmore, D.K., Jolly, R.D., Harris, R.E. and Marsden, N.A. 1979. Petechial hemorrhages in carcass fat of slaughtered lambs. New Zealand Vet. $J$. $27: 181-4,189$.

U.S. Navy. 1968. U.S. Naval Flight Surgeon's Manual. Bio-Technology Inc., Arlington, Virginia.

Van der Wal, P.G., Eikelenboom, G. and Lambooy, E. 1983. The effect of electrical stunning on meat quality. In: Eikelenboom, G. ed. Stunning Animals for Slaughter. Boston: Martinus Nijhoff. pp. 83-89.

Van der Wal, P.G. 1976. Bone fractures in pigs as a consequence of electrical stunning. European Meeting of Meat Research Workers, Proceedings, Vol. 1. (C3:1, C3:4).

Van der Wal, P.G. 1978. Chemical and physiological aspects of pig stuming in relation to meat quality--A review. Meat Sci. 2:19-30.

Vecchio, R.J. 1977. Physiological Aspects of Flight. New York: Dowling College Press.

Veercamp, C.H. and de Vries, A.W. 1983. Influence of electrical stunning on quality aspects of broilers. In: Eikelenboom, G. ed. Stunning of Animals for Slaughter. Boston: Martinus Nijhoff. pp. 197-207.

Warrington, P.D. 1974. Electrical stunning: A Review of the literature. Vet. Bulletin. 44:617-33.

Warriss, P.D. 1984. Exsanguination of animals at slaughter and the residual blood content of meat. Vet. Rec. 115:202-205.

Warriss, P.D. and Wotton, S.B. 1981. Effect of cardiac arrest on exsanguination in pigs. Research Vet. Sci. 31:82-86.

Weaver, L.A., Ives, J.O., Williams, R. and Nies, A. 1977. A comparison of standard alternating current and low energy brief-pulse electrotherapy. Biol. Psych. 12:525-43.

Weise, V.E., Schutt, I. and Levetzow, R. 1982. Effects of stunning broilers by means of alternating current on meat quality. Berl. Munch Tieraztle. 95:241-7. 